\title{
Comparative Effect Of Curcumin Versus Liposomal Curcumin On Systemic Pro-Inflammatory Cytokines Profile, MCP-I And RANTES In Experimental Diabetes Mellitus
}

This article was published in the following Dove Press journal:

International Journal of Nanomedicine

\author{
Adriana Elena Bulboacă $\mathbb{D}^{1}$ \\ Paul Mihai Boarescu' \\ Sorana D Bolboacă $\mathbb{1}^{2}$ \\ Mihai Blidaru' \\ Dana Feștilă ${ }^{3}$ \\ Gabriela Dogaru ${ }^{4}$ \\ Cristina Ariadna Nicula (1D ${ }^{5}$ \\ 'Pathophysiology Department, luliu \\ Hațieganu University of Medicine and \\ Pharmacy Cluj-Napoca, Cluj-Napoca, \\ Romania; ${ }^{2}$ Department of Medical \\ Informatics and Biostatistics, luliu \\ Hațieganu University of Medicine And \\ Pharmacy, Cluj-Napoca, Romania; \\ ${ }^{3}$ Department of Maxillofacial Surgery and \\ Radiology, luliu Hațieganu University of \\ Medicine and Pharmacy, Cluj-Napoca, \\ Romania; ${ }^{4}$ Department of Physical \\ Medicine and Rehabilitation, luliu \\ Hațieganu University of Medicine and \\ Pharmacy, Cluj-Napoca, Romania; \\ ${ }^{5}$ Department of Ophthalmology, luliu \\ Hațieganu University of Medicine and \\ Pharmacy Cluj-Napoca, Cluj-Napoca, \\ Romania
}

Purpose: Anti-inflammatory proprieties of curcumin were proved to be useful in various diseases, including diabetes mellitus. The aim of this study was to assess the anti-inflammatory comparative effect of curcumin solution with liposomal curcumin formula, regarding the improvement of serum levels of TNF- $\alpha$ (tumor necrosis factor-alpha), IL-6 (interleukin), IL-1 $\alpha$, IL-1 $\beta$, MCP-1 (monocyte chemoattractant protein-1) and RANTES in experimental diabetes, induced by streptozotocin (STZ), in rats.

Materials and methods: Six groups of 7 rats were investigated regarding the effect of i.p. (intraperitoneal) administration of two concentrations of curcumin solution (CC1 and CC2) and two concentrations of liposomal curcumin (LCC1 and LCC2): group 1 - control group with i.p. administration of $1 \mathrm{~mL}$ saline solution, group 2 - i.p. STZ administration $(60 \mathrm{mg} / \mathrm{kg}$ bw, bw=body weight), group $3-\mathrm{STZ}+\mathrm{CC} 1$ administration, group $4-\mathrm{STZ}+\mathrm{CC} 2$ administration, group $5-\mathrm{STZ}$ + LCC1 administration and group $6-\mathrm{STZ}+\mathrm{LCC} 2$ administration. The concentrations of curcumin formulas were $1 \mathrm{mg} / 0.1 \mathrm{~kg}$ bw for CC1 and LCC1 and $2 \mathrm{mg} / 0.1 \mathrm{~kg}$ bw for CC2 and LCC2, respectively. Serum levels of C-peptide (as an indicator of pancreatic function) and TNF- $\alpha$, IL-6, IL-1 $\alpha$, IL-1 $\beta$, MCP-1, and RANTES (as biomarkers for systemic inflammation) were assessed for each group.

Results: The plasma level of C-peptide showed significant improvements when LCC was administrated, with better results for LCC2 when compared to LCC1 $(\mathrm{P}<0.003)$. LCC2 pretreatment proved to be more efficient in reducing the level of TNF- $\alpha(\mathrm{P}<0.003)$ and RANTES $(\mathrm{P}<0.003)$ than $\mathrm{CC} 2$ pretreatment. Upon comparing LCC2 with LCC1 formulas, the differences were significant for TNF- $\alpha(\mathrm{P}=0.004)$, IL-1 $\beta(\mathrm{P}=0.022)$, and RANTES $(\mathrm{P}=0.003)$ levels.

Conclusion: Liposomal curcumin in a dose of $2 \mathrm{mg} / 0.1 \mathrm{~kg}$ bw proved to have an optimum therapeutic effect as a pretreatment in DM induced by STZ. This result can constitute a base for clinical studies for curcumin efficiency as adjuvant therapy in type $1 \mathrm{DM}$.

Keywords: diabetes mellitus, inflammation, curcumin, cytokine

\section{Introduction}

Curcumin, a yellow pigment in the Indian spice Turmeric (Curcuma longa), is known for its therapeutic effects and proved its anti-inflammatory activity through the suppression of oxidative stress, playing a role of scavenger molecule. ${ }^{1}$ Anti-inflammatory properties of curcumin are only partially related to the anti-oxidative mechanism, having been demonstrated to influence other cell signaling pathways, including the
Correspondence: Sorana D Bolboacă Department of Medical Informatics and Biostatistics, luliu Hațieganu University of Medicine and Pharmacy, Louis Pasteur Str., No. 6, 400349, Cluj-Napoca, Romania

Tel +40374834506

Email sbolboaca@umfcluj.ro 
nuclear factor $\kappa \mathrm{B}(\mathrm{NF}-\kappa \mathrm{B})$, prostaglandins and pro-inflammatory cytokine production such as tumor necrosis factoralpha (TNF- $\alpha$ ) and interleukin (IL)-1 $\beta .^{1-4}$ Based on these facts, numerous researches aim to explore the anti-inflammatory activity of curcumin for a better understanding of their action mechanisms. The main issue of clinical efficacy of curcumin, as adjuvant therapy, is its low bioavailability. ${ }^{4}$ Therefore, efforts have been dedicated to develop a new curcumin formulation and to study a new administration route for a better bioavailability and tissues distribution. ${ }^{4}$ Despite its low bioavailability, curcumin proved to be safe and has good tolerability and effectiveness in various human diseases. ${ }^{5}$ New approaches include the combination of curcumin with adjuvant molecules or designed synthetic analogs. ${ }^{6,7}$ To overcome its low bioavailability, researchers have also tried to explore new curcumin delivery systems by encapsulating the compound in various micelles, phospholipid complexes, liposomes or nanoparticles structures and to explore parenteral administration routes. ${ }^{6,8-10}$

Moreover, it has been previously proved that nanocurcumin is efficient in reducing inflammation in streptozotocin (STZ) induced experimental diabetes mellitus (DM). ${ }^{11}$ Ganugula et al reported that oral administration of curcumin by gavage (both a single dose and multiple doses for 28 days prior DM induction), succeeded in reducing plasma levels of IL-1 $\alpha$ (interleukin), G-CSF, IL-10, IL-17A, IL-1 $\beta$, IL-6, TNF- $\alpha$, IL-4, GM-CSF, IFN- $\gamma$, IL-2, IL-5, IL-13, IL-12p70. ${ }^{11}$ Water insoluble curcumin is able to forms highly aqueous soluble complexes, with a safe $\mathrm{pH}^{12}$ In mice, these complexes increased peak plasma concentration of curcumin by 6 times and oral bioavailability by $\sim 20$ times. $^{12}$ Since several animal studies reported that the majority of oral administration of curcumin is excreted in the feces $(\leq 90 \%),{ }^{13}$ a new administration route and formula could improve its bioavailability. Liposomal curcumin nanoformulation has a better bioavailability in various diseases; therefore, it could represent an optimal delivery system for therapies. ${ }^{14}$ Liposomes consist of phospholipid bilayer vesicles (with a diameter varying from $25 \mathrm{~nm}$ to $1000 \mathrm{~nm}$ ) that can carry both hydrophobic and hydrophilic drugs. ${ }^{15}$ Intravenous administration of liposomal curcumin was shown to be more efficient due to the enhancement of their stability and targeting proprieties. ${ }^{14}$ Intraperitoneal administration of curcumin results in a detectable concentration of the compound (by high-performance liquid chromatography) in the brain tissue. ${ }^{16}$ Based on this report, there is evidence that liposomal curcumin can penetrate even the tight junction of the blood-brain barrier. This characteristic is essential for the potential effect of curcumin on vascular complications of diabetes mellitus. Liposomal formula improved the accumulation of encapsulated drugs in organs and tissues and was demonstrated to increase their therapeutic actions and reduce their side effects. ${ }^{17}$ Therefore, the pharmaceutical form and the administration route are essential factors for therapeutic efficiency.

To the best of our knowledge, the efficacy of liposomal curcumin formulation was previously assessed only in experimental type 2 diabetes mellitus in rats. ${ }^{18}$ Diabetes mellitus type 1 is one of the most critical diseases associated with inflammation, which plays an essential role in the $\beta$-cell destruction process. ${ }^{19}$ The clinical symptomatology of type $1 \mathrm{DM}$ is seen when $70-80 \%$ of pancreatic beta cells are already destroyed. ${ }^{20}$ No known biomarkers can assess the pancreatic cells destruction for individuals who are at risk for DM type 1, or for those patients who already developed DM type $1 .^{20}$ Consequently, one of the most important goals of the current investigations is to find valuable biomarkers in order to evaluate the pancreatic function and inflammation associated with pancreatic insult. After the damage of islet cells, the pancreatic tissue is infiltrated by inflammatory cells that are activated, and as a consequence, pro-inflammatory cytokines are produced. $^{21}$ An inflammatory reaction will result, triggered and amplified by several molecules that are proinflammatory mediators, which are released by different types of cells such as leukocytes, endothelial cells, or injured cells. $^{22}$ The pro-inflammatory molecules have a critical role in diabetes mellitus complications. ${ }^{23-25}$ Proinflammatory cytokines synthesis can be induced by the excessive production of reactive oxygen species (ROS), via redox-dependent signaling pathways. ${ }^{19}$ The balance disruption between oxidative stress and anti-oxidative molecules can propagate the destruction of the cells and, consequently, can enhance the inflammatory reaction.

Tumor necrosis factor-alpha $(\mathrm{TNF}-\alpha)$ is one of the most important cytokines, produced primarily by activated macrophages, neutrophils, and lymphocytes involved in diabetes mellitus pathogenesis. ${ }^{26}$ Patients with type 1 DM have been demonstrated to have an increased serum level of TNF- $\alpha$ which contributes to systemic inflammation. ${ }^{27,28}$ Other various types of pro-inflammatory cytokines such as IL-1 $\beta$ (interleukin), the IL-6 family, ${ }^{29}$ IL-8, or MCP-1 (monocyte chemoattractant protein- 1$)^{30}$ have been suggested to be involved in DM pathogenesis. Padgett et al $^{19}$ showed that pro-inflammatory cytokines could be involved in islet cells death by 
triggering the apoptotic or necrotic process. IL-6 has also been suggested to be a molecule able to regulate the glucose metabolism by acting directly on pancreatic cells and other types of cells such as skeletal muscle cells, adipocytes, hepatocytes, and neuroendocrine cells. ${ }^{29}$ Besides its functions as a chemoattractant protein, MCP-1 which is produced by inflammatory cells, can also induce cellular death via oxidative stress pathway. ${ }^{31}$ In addition, Regulated on Activation, Normal $\mathrm{T}$ Cell Expressed and Secreted (RANTES), a group of molecules contributing to the enrollment of leukocytes in inflammatory process, can also contribute to DM type 1 pathogenesis. ${ }^{32}$ However, their exact role in the beta-cell destruction mechanism is still under research. ${ }^{32}$ Beta cells have a temporally limited capacity to recover from cytokine action, by repairing the DNA damage, and by improving insulin secretion if the cytokine action is shorter than 24 hrs. $^{33}$ After this, irreversible cell destruction will result. $^{33}$ The pro-inflammatory cytokines stimulate an early necrotic process of islet cells, that can be turned to late apoptosis if the cytokine action is longer than $36 \mathrm{hrs}^{34}$ Streptozotocin (STZ) induced DM is one of the most used experimental models to study diabetes mellitus-associated inflammation induced by STZ cytotoxic effect on beta-pancreatic cells. ${ }^{35}$ Therefore, rapid modulation of proinflammatory cytokines could be one of the most important contributors to reducing beta-cells destruction, due to an associated inflammatory process. We previously demonstrated the anti-oxidant properties of curcumin for experimental diabetes mellitus induced by STZ, in oral administration and for liposomal curcumin in i.p. administration. ${ }^{10,36}$

To go beyond of the previously presented state-of-theart, the purpose of this study was to assess the effect of intraperitoneal administration of liposomal curcumin in experimental diabetes on C-peptide level (as a marker of pancreatic function) and on pro-inflammatory cytokines (TNF- $\alpha$, IL-6, IL-1 $\alpha$, IL-1 $\beta$ ), MCP-1, and RANTES as markers of systemic inflammatory reaction.

\section{Materials And Methods}

All the experimental procedures applied in this study were approved by Ethical Committee of Iuliu Haţieganu University of Medicine and Pharmacy (UMF) ClujNapoca, Romania (protocol approval no.0374/16.10.2018) and followed the rules of the European Convention for the protection of Vertebrate Animals used for Experimental and other Scientific Purposes. The animals were procured from the Animal Department of UMF Cluj-Napoca, Romania, and were kept in polypropylene cages at Pathophysiology Department. Wistar-Bratislava albino male rats, weighing 200-250 g with unrestricted access to food (standard pellets from Cantacuzino Institute, Bucharest, Romania) and water were used for this experiment. The animals were kept at constant temperature $\left(24 \pm 2^{\circ} \mathrm{C}\right)$, humidity $(60 \pm 5 \%)$ and light-dark regime. All the efforts were made in order to reduce the animals' suffering and the number used for this experiment.

\section{Preparation Of Liposomal Curcumin}

Liposomal-curcumin was encapsulated in long-circulating liposomes (LCL) using the film hydration method with a lipid molar ratio of 9.5:0.5:1 (DPPC:PEG-2000-DSPE: $\mathrm{CHO})$ as previously described. ${ }^{37,38}$ Briefly, we used 70 $\mathrm{mM}$ concentration of phospholipids of which $66.5 \mathrm{mM}$ 1,2-dipalmitoyl-sn-glycero-3-phosphocholine (DPPC), the main lipid, and $3.5 \mathrm{mM} \mathrm{N}$-(carbonyl-methoxypolyethyleneglycol-2000)-1,2-distearoyl-sn-glycero-3-phosphoethanolamine (PEG-2000-DSPE), to obtain long circulation properties for a higher efficiency. Further, cholesterol was added to the mixture, resulting in 10:1 phospholipids to cholesterol molar ratio. Resulting PEG-coated nanoliposomes had a size around $140 \mathrm{~nm}$; polydispersity value, close to 0.1 ; and a zeta potential of about $-50 \mathrm{mV}$. The particle size and particle size distribution of liposomes were determined by dynamic light scattering using a Zetasizer Nano ZS instrument (Malvern Instruments, Malvern, UK). Immediately after the preparation, the size, size distribution, and surface charge of the liposomes were determined, upon dilution in a ratio of 1:100. The method assigns an efficient encapsulation of curcumin into the liposomes. The resulting liposomal curcumin nanoparticles contained a relatively high concentration of curcumin, around $4.7 \mathrm{mg} / \mathrm{mL}$, with an high efficiency, close to $80 \%$.

The proposed formulation had appropriate quality attributes for intraperitoneal administration, such as monodisperse size around $140 \mathrm{~nm}$ and zeta potential about $-50 \mathrm{mV}$. The same concentration of curcumin solution was freshly prepared by dissolution in $96 \%$ $(\mathrm{v} / \mathrm{v})$ ethanol and further dilution with saline, in order to observe if liposomal encapsulation curcumin had an increased therapeutic effect compared to curcumin solution. Curcumin (CC) and cholesterol were purchased from Sigma-Aldrich Co (St. Louis, MO, USA). 1,2-Dipalmitoyl-sn-glycero-3-phosphocholine (DPPC, 
$\geq 99 \% \quad$ [TP-PC]) and N-(carbonyl-methoxypolyethylenglycol-2000)-1,2-distearoyl-sn-glycero-3phosphoethanolamine (PEG-2000-DSPE, $\geq 98 \%$ [HPLC]) sodium salt were purchased from Lipoid $\mathrm{GmbH}$ (Ludwigshafen, Germany).

\section{Experimental Protocol}

Six groups of male rats, as presented in Figure 1 were evaluated.

Streptozotocin was administrated as a single dose by intraperitoneal route $(60 \mathrm{mg} / \mathrm{kg}$ bw $-1 \mathrm{~mL}$ solution) after dissolving it in freshly prepared $0.01 \mathrm{M}$ citrate buffer $(\mathrm{pH}=4.5)$ solution. $^{39}$ All curcumin treatments were made 30 mins before STZ administration. ${ }^{10}$ A single dose of curcumin was administrated in our study since previous studies demonstrated the efficacity of one prophylactic dose of curcumin in various form (curcumin-capped iron oxide nanoparticles ${ }^{40}$ or liposomal curcumin ${ }^{10}$ ) and in different pathological conditions such as: nano-curcumin in type $1 \mathrm{DM},{ }^{11}$ injected microparticles of curcumin in cancer, $^{41}$ or type $1 \mathrm{DM}^{42}$ All the animals with plasma glucose above $200 \mathrm{mg} / \mathrm{dL}$ at $72 \mathrm{hrs}$ were considered diabetic and were included in the study. ${ }^{11}$ Streptozotocin was purchased from Sigma-Aldrich Co. (St Louis, MO, USA).

\section{Blood Collection And Pancreatic Function Assessment}

The blood parameters were assessed from samples collected from the retro-orbital plexus of each animal, under ketamine anaesthesia $(5 \mathrm{mg} / \mathrm{kg} \text { bw, i.p. route })^{43}$ at the end of the experiment $(72 \mathrm{hrs})$. The effect of liposomal curcumin on glycemia (as a parameter of pancreatic function), alanine aminotransferase (ALT) and aspartate aminotransferase (AST) (as parameters of liver cell damage) have already been reported. ${ }^{10}$ The serum C-peptide was measured as marker of pancreatic beta-cell function. C-peptide (connecting peptide) connects insulin's A-chain to its B-chain in proinsulin molecule. It is co-secreted with insulin by pancreatic $\beta$-cells following glucose stimulation, and it is a good indicator of pancreatic function. ${ }^{44,45}$ The C-peptide determination was done with the ELISA method (kit purchased from Elabscience, USA).

\section{Multiplex Assay For Cytokines}

The serum assessment for tumour necrosis factor-alpha (TNF- $\alpha$ ), interleukin 6 (IL-6), interleukin-1 alpha (IL-1 $\alpha$ ), interleukin-1 beta (IL-1 $\beta$ ), monocyte chemoattractant protein-1 (MCP-1), and regulated upon activation, normal $\mathrm{T}$ cell expressed and secreted (RANTES), was made by ELISA technique (Stat Fax 303 Plus Microstrip Reader, Minneapolis, USA) with a kit purchased from Signosis Inc., Santa Clara, CA, USA.

\section{Statistical Analysis}

Statistical analysis was applied to the raw data of the investigated biomarkers. Descriptive statistics, represented by mean and standard deviation, was reported for the investigated biomarkers. The number of rats per group imposed the application of non-parametric methods when the STZ groups were compared (as the Kruskal-Wallis

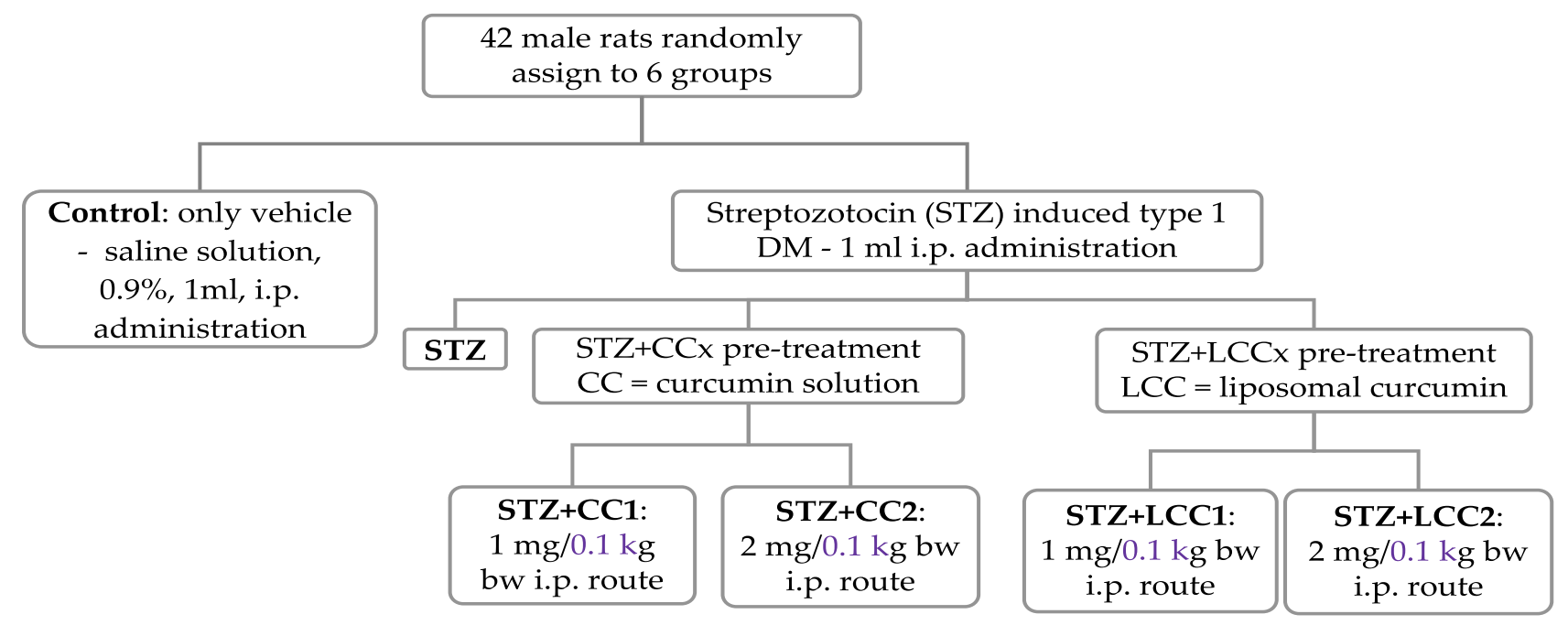

Figure I Group flow chart: experimental design.

Abbreviations: i.p., intraperitoneal administration; bw, body weight. 
test) or when two groups were compared (the MannWhitney test). The number of investigated groups was used to adjust the significance level, and a p-value of less than 0.01 was considered statistically significant. The variability of biomarkers by groups was graphically represented with box-and-whiskers with the line in the box given by the value of median, $x$ representing the value of the mean, the lower and upper box as 1 st and 3rd quartile, and the whiskers as the minimum and maximum values. Statistica program (v. 13.5, StatSoft, Tulsa, OK, USA) was used to perform the analysis.

\section{Results}

All the rats included in the study were analyzed. The values of C-peptide show the damage induced by STZ, with significant differences between diabetic rats (Kruskal-Wallis ANOVA: statistics $=22.88 ; \mathrm{P}=0.0001$ ) and significant smaller values (see Figure 2A) for each group as compared to the control group (two-group comparisons by Mann-Whitney test: P-values $=0.0022$ ). The values of TNF- $\alpha$ (Figure 2B), IL-6 (Figure 2C), IL-1 $\alpha$ (Figure 2D), IL-1ß (Figure 2E), MCP-1 (Figure 2F), and RANTES (Figure 2G) were significantly higher in the STZ group compared to the control group (P-value $<0.0001$ ).

Kruskal-Wallis test identified significant differences among STZ, STZ $+\mathrm{CC} 1, \mathrm{STZ}+\mathrm{CC} 2, \mathrm{STZ}+\mathrm{LCC} 1$, and $\mathrm{STZ}+\mathrm{LCC} 2$ groups for all investigated markers: C-Peptide $($ Stat $=22.88 ;$ P-value $=0.0001)$, TNF- $\alpha$ $($ Stat $=25.15 ;$ P-value $<0.0001)$, IL-6 $($ Stat $=13.76$; $\mathrm{P}$-value $=0.0081)$, IL-1 $\alpha($ Stat $=19.75 ;$ P-value $=$ 0.0006), IL-1 $\beta$ (Stat $=27.81 ; \quad$-value $<0.0001)$, MCP-1 $($ Stat $=16.90 ;$ P-value $=0.0020)$, RANTES $($ Stat $=28.22 ;$ P-value $<0.0001)$.

\section{Discussions}

\section{Curcumin And Pancreatic Function}

\section{Alleviation}

The question of this study was whether different levels of C-peptide, pro-inflammatory cytokines (TNF- $\alpha$, IL-6, IL-1 $\alpha$, IL-1ß), MCP-1, and RANTES could be useful to assess the efficiency of curcumin pretreatment in two pharmaceutical formulas, and two different concentrations, in STZ-induced type $1 \mathrm{DM}$ in rats. To the extent of our knowledge, this is the first study of assessing the antiinflammatory efficacy of liposomal curcumin administration by intraperitoneal route in STZ-induced type $1 \mathrm{DM}$ in rats.
We found that the C-peptide level in the group with STZ and CC and LCC administration was improved compared to STZ group with better results for LCC when compared to $\mathrm{CC}$ solution (Table 1, Figure 2). We also obtained better results for C-peptide level with LCC2 pretreatment when compared to LCC1 (P-value $=0.0022$ ) (Table 1, Figure 2A) proving that curcumin acts in a dosedependent manner. The significant improvement of C-peptide in groups pretreated with curcumin show that the pancreatic beta-cell function can be partially preserved by this therapy with better results for a higher concentration of liposomal curcumin. The value of $\mathrm{C}$-peptide can offer a measure of pancreatic cell activity that is preferable to insulin measurement because of the slower metabolic clearance rate (half-life of 20-30 mins, compared to the half-life of insulin of just 3-5 mins); it is also preferred in humans, because of the lack of cross-reactivity with antibodies to insulin. ${ }^{46}$ Due to a lower metabolic rate of C-peptide, compared to the metabolic rate of insulin, $\mathrm{C}$-peptide provides a more stable test window of fluctuating beta-cell response. ${ }^{47} \mathrm{C}$-peptide results from pro-insulin in equimolar concentration with insulin. ${ }^{45,48}$ After the cleavage of proinsulin, insulin and C-peptide are produced in pancreatic beta cells in equal amounts. ${ }^{47}$ Therefore, the evaluation of the C-peptide as an indicator of pancreatic function demonstrated that curcumin administration prior to STZ can improve the pancreatic production of insulin. Rat islet amyloid polypeptide (hIAPP) aggregation (rIAPP) is a new approach that also could serve as biomarker in experimental studies for therapeutic agent efficacy assessment. ${ }^{49}$ This new molecular perspective regarding the early processes associated with islet cells destruction could bring a better understanding of pathophysiological mechanisms involved in type $1 \mathrm{DM}$.

Moreover, data from experimental studies in rats showed that C-peptide is beneficial for the effect of insulin on glycemia and glucose utilization. ${ }^{50-52}$ These effects could be explained by the increased utilization of glucose due to increased muscle glucose uptake, but the exact pathway involved in this effect of C-peptide is still unknown. ${ }^{53}$ Experimental studies demonstrated that the effect of C-peptide on lipidic metabolism consists in reducing lipolysis in diabetic rats. ${ }^{54}$ Still, the effect of C-peptide on lipolysis in non-diabetic conditions has been showed to be insignificant. ${ }^{55}$ On a different note, the effect of C-peptide on circulation consists in a vasodilator effect (due to the enhancement of nitric oxide synthesis by increasing the expression of endothelial nitric 

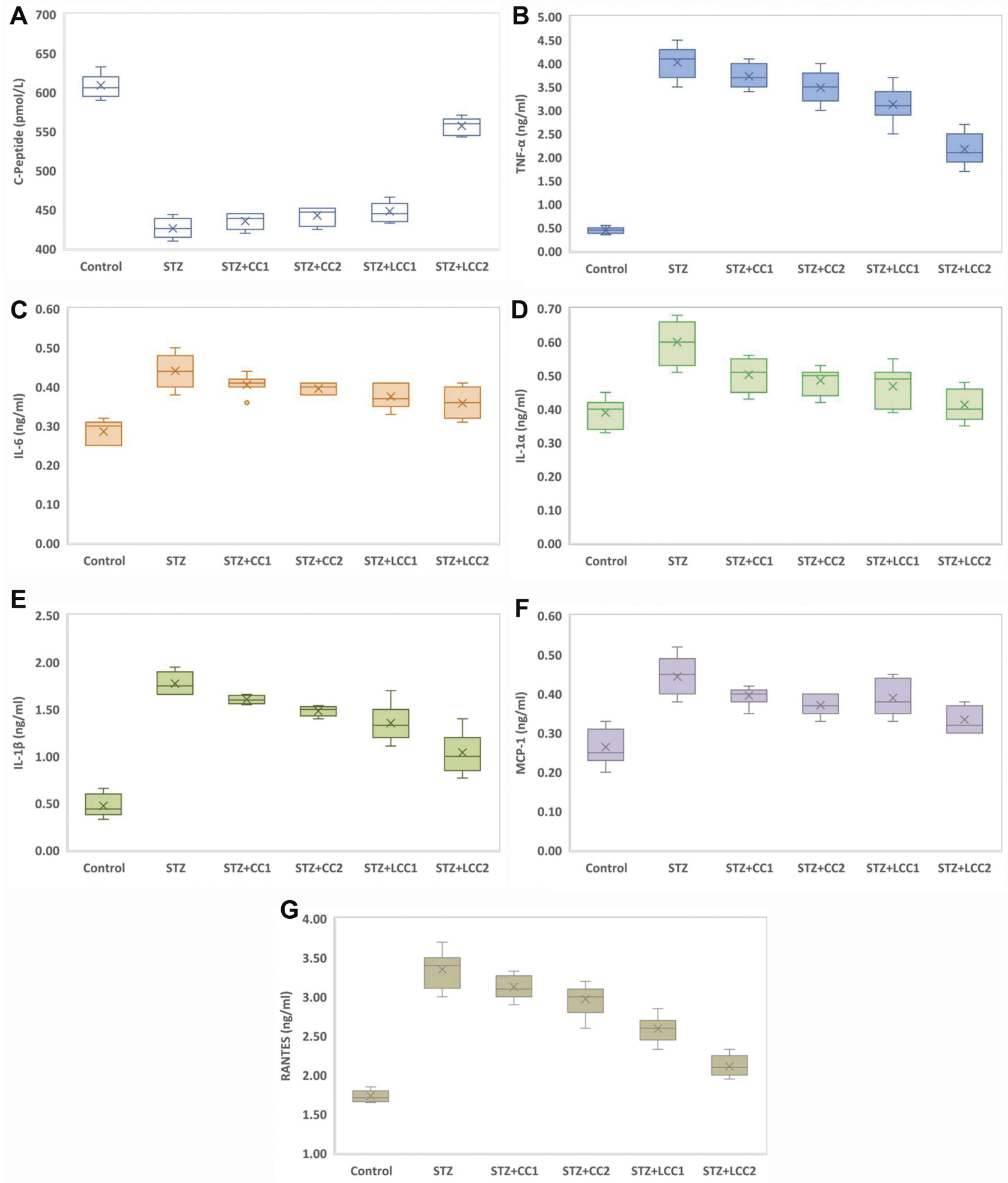

Figure 2 Variability of the biomarkers by groups: (A) C-Peptide; (B) tumor necrosis factor-alpha (TNF- $\boldsymbol{\alpha}$ ); (C) interLeukin 6 (IL-6); (D) interLeukin I alpha (IL- I $\boldsymbol{\alpha}$ ); (E) interLeukin I beta (IL-I $\beta$ ); (F) monocyte chemoattractant protein-I (MCP-I); (G) regulated on activation, normal t cell expressed and secreted (RANTES); Control; STZ = streptozotocin-induced type I diabetes; STZ+CCx = streptozotocin-induced type I diabetes with curcumin solution pre-treatment at I mg/0.I $\mathrm{kg}$ bw $(x=\mathrm{I}$, CCI), respectively, $2 \mathrm{mg} / 0 . \mathrm{lg}$ bw $(x=2, C C 2)$; STZ+LCCx = streptozotocin-induced type I diabetes with liposomal curcumin pre-treatment at I mg/0.I $\mathrm{kg}$ bw $(x=\mathrm{I}, \mathrm{LCCl})$ respectively, $2 \mathrm{mg} / 0.1 \mathrm{~kg}$ bw $(\mathrm{x}=2$, LCC2).

Abbreviations: TNF- $\alpha$, tumour necrosis factor-alpha; IL-6, interleukin 6; IL-I $\alpha$, interleukin-I alpha; IL-I $\beta$, interleukin-I beta; MCP-I, monocyte chemoattractant protein-I; RANTES, regulated upon activation, normal T cell expressed and secreted. 
Table I Variability In The Investigated Marker Of Pancreatic Damage, And Cytokines By Groups Expressed As Mean And Standard Deviation

\begin{tabular}{|c|c|c|c|c|c|c|}
\hline & \multicolumn{6}{|c|}{ Group Abbreviation (7 rats per group) } \\
\hline & C & STZ & STZ+CCI & STZ+CC2 & STZ+LCCI & STZ+LCC2 \\
\hline \multicolumn{7}{|c|}{ Marker of pancreatic damage } \\
\hline \multicolumn{7}{|l|}{ C-Peptide (pmol/L) } \\
\hline Mean (STD) & $609(14.80)$ & $426(12.91)$ & $436(9.69)$ & $443(11.19)$ & $448(12.14)$ & $557(11.00)$ \\
\hline P-value* & & & 0.1417 & 0.0298 & 0.0127 & 0.0022 \\
\hline P-value ${ }^{* *}$ & & & & & 0.1059 & 0.0022 \\
\hline P-value*** & & & & & & 0.0022 \\
\hline \multicolumn{7}{|c|}{ Markers of inflammation } \\
\hline \multicolumn{7}{|l|}{ TNF- $\alpha(n g / m L)$} \\
\hline Mean (STD) & $0.45(0.07)$ & $4.03(0.35)$ & $3.73(0.26)$ & $3.49(0.35)$ & $3.13(0.39)$ & $2.17(0.35)$ \\
\hline P-value* & & & 0.1102 & 0.0253 & 0.0040 & 0.0022 \\
\hline P-value** & & & & & 0.0106 & 0.0022 \\
\hline P-value*** & & & & & & 0.0040 \\
\hline \multicolumn{7}{|l|}{ IL-6 (ng/mL) } \\
\hline Mean (STD) & $0.29(0.03)$ & $0.44(0.04)$ & $0.41(0.02)$ & $0.40(0.01)$ & $0.38(0.03)$ & $0.36(0.04)$ \\
\hline P-value* & & & 0.1599 & 0.0553 & 0.0152 & 0.0106 \\
\hline P-value** & & & & & 0.0967 & 0.0967 \\
\hline P-value*** & & & & & & 0.4062 \\
\hline \multicolumn{7}{|l|}{$\mathrm{IL}-\mathrm{I} \alpha(\mathrm{ng} / \mathrm{mL})$} \\
\hline Mean (STD) & $0.39(0.04)$ & $0.60(0.07)$ & $0.50(0.05)$ & $0.49(0.04)$ & $0.47(0.06)$ & $0.4 \mathrm{I}(0.05)$ \\
\hline P-value* & & & 0.0181 & 0.0060 & 0.0060 & 0.0022 \\
\hline P-value** & & & & & 0.2248 & 0.0181 \\
\hline $\mathrm{P}$-value*** & & & & & & 0.0845 \\
\hline \multicolumn{7}{|l|}{ IL-Iß (ng/mL) } \\
\hline Mean (STD) & $0.47(0.12)$ & $1.77(0.12)$ & I.6I (0.04) & $1.48(0.05)$ & $1.35(0.21)$ & $\mathrm{I} .04(0.2 \mathrm{I})$ \\
\hline P-value* & & & 0.0033 & 0.0022 & 0.0060 & 0.0022 \\
\hline P-value** & & & & & 0.0298 & 0.0027 \\
\hline P-value $* * *$ & & & & & & 0.0215 \\
\hline \multicolumn{7}{|l|}{ MCP-I (ng/mL) } \\
\hline Mean (STD) & $0.26(0.05)$ & $0.44(0.05)$ & $0.40(0.02)$ & $0.37(0.03)$ & $0.39(0.05)$ & $0.33(0.03)$ \\
\hline P-value* & & & 0.1102 & 0.0106 & 0.0639 & 0.0027 \\
\hline P-value** & & & & & 0.7983 & 0.0736 \\
\hline P-value*** & & & & & & 0.0409 \\
\hline \multicolumn{7}{|l|}{ RANTES (ng/mL) } \\
\hline Mean (STD) & I.73 (0.07) & $3.35(0.24)$ & $3.13(0.16)$ & $2.97(0.21)$ & $2.60(0.17)$ & $2.11(0.13)$ \\
\hline P-value* & & & 0.0639 & 0.0152 & 0.0022 & 0.0022 \\
\hline P-value** & & & & & 0.0022 & 0.0022 \\
\hline P-value*** & & & & & & 0.0027 \\
\hline
\end{tabular}

Notes: P-values from Mann-Whitney test: *As compared to STZ-C; **For comparison of STZ+CCI with STZ+LCCI, respectively, STZ+CC2 with STZ+LCC2; ***For comparison between groups with different doses of LLC (STZ+LCCI with STZ+LCC2).

Abbreviations: STD, standard deviation; C, Control; STZ, streptozotocin-induced type I diabetes; STZ+CCl, STZ and I mg/0.I kg bw curcumin as pre-treatment; STZ $+\mathrm{CC} 2$, STZ and $2 \mathrm{mg} / 100 \mathrm{~g}$ bw curcumin as pre-treatment; STZ+LCCI, STZ and pre-treatment with I mg/I00g bw liposomal-curcumin; STZ+LCC2, STZ and pre-treatment with $2 \mathrm{mg} / 0 . \mathrm{l} \mathrm{kg}$ bw liposomal-curcumin; Std, standard deviation; TNF- $\alpha$, tumour necrosis factor-alpha; IL-6, interleukin 6; IL-I $\alpha$, interleukin-I alpha; IL-I $\beta$, interleukin-I beta; MCP-I, monocyte chemoattractant protein-I; RANTES, regulated upon activation, normal T cell expressed and secreted.

oxide synthase). ${ }^{56}$ Thus, C-peptide exerts a protective role retinopathy, ${ }^{57}$ diabetic nephropathy, ${ }^{58}$ or diabetic against DM microvascular complications such as diabetic neuropathy. ${ }^{57}$ Low or undetectable levels of C-peptide 
are associated with severe forms of diabetic retinopathy, namely proliferative retinopathy. ${ }^{59,60}$ The nephroprotective effect of C-peptide is related to the decrease of apoptosis induced by pro-inflammatory cytokines ${ }^{61}$ and to the interaction with the signaling pathway of growth factors. ${ }^{62}$ C-peptide can improve sensory, and motor nerve conduction velocity in STZ-induced diabetes in rats ${ }^{63}$ and can reduce the neural $\mathrm{Na}^{+}, \mathrm{K}^{+}$-ATPase defect in the hippocampus. ${ }^{64}$ The preservation of C-peptide secretion can result in better metabolic control and less microvascular complications. ${ }^{65}$ The C-peptide can also have a protective effect on vasculature against inflammation in type 1 DM. ${ }^{66}$ Therefore, the partial preservation of C-peptide production by beta-pancreatic cells by curcumin administration, proved by our study, can constitute a valuable strategy in DM treatment. Moreover, C-peptide assessment could bring valuable information regarding the risk of microvascular complications in DM.

\section{Liposomal Curcumin Effect On Proinflammatory Cytokines}

The data presented in this study showed a statistically significant (Table 1) increase in proinflammatory cytokines (TNF- $\alpha$ - Figure 2B, IL-6 - Figure 2C, IL-1 $\alpha$ - Figure 2D, and IL- $1 \beta$ - Figure $2 \mathrm{E}$ ) after STZ administration. Some reports suggested that the increase of oxidative stress molecules due to STZ administration can induce and can constitute biochemical markers for the pathogenesis of type 1 DM. ${ }^{10,67}$ Fatima et al ${ }^{58}$ also found decreased levels of catalase and superoxide dismutase in patients with type 1 DM, suggesting a reduced antioxidant activity. Particularly, nitro-oxidative stress enhancement, by increasing the production of $\mathrm{NO}$, contributes to the injury of pancreatic beta cells, and to the cell death by apoptosis and necrosis. ${ }^{68}$ On the other hand, hyperglycemia itself can be considered responsible for molecular and cellular damages. ${ }^{69}$ Due to the impossibility to regulate their intracellular level of glucose (consequently to the lack of insulin) cells are vulnerable to hyperglycemia, which can lead to changes in their redox status. ${ }^{69}$ Cells' redox status disequilibrium is closely related to the enhancement of pro-inflammatory activity because the energy metabolism of the cells and the redox state are intrinsically related. ${ }^{70}$ In fact, decreased intracellular glucose increases ROS production and substantially contributes to inflammatory reaction initiation and cell apoptosis. ${ }^{70}$ Activated macrophages and neutrophils arrived at the inflammation site, are the primary sources of ROS generation and pro-inflammatory cytokines production. ${ }^{71}$ Two types of macrophages have been described, the classically activated macrophages that produce pro-inflammatory cytokines (inducing insulitis and beta-cells death by apoptosis and necrosis) and alternatively activated macrophages, with anti-inflammatory activity, both showing an important role in type 1 and type 2 DM pathogenesis. ${ }^{71}$ The imbalance between these two types of macrophages could represent an important mechanism involved in diabetes mellitus pathogenesis. Activation of different signaling pathways in inflammatory cells is associated with increased production of IL-1 $\beta$, IL-6, and TNF- $\alpha .{ }^{72}$ Our results also demonstrated a significant increase of TNF- $\alpha$, IL-6, IL- $1 \alpha$, and IL- $1 \beta$ after STZ administration. We also found that the effectiveness of curcumin pretreatment depends on the formula (LCC2 was more effective than $\mathrm{CC} 2$ for TNF- $\alpha$, IL- $1 \beta$ levels improvement; $\mathrm{P}<0.01$ ) (Figure 2, Table 1). Dose-related effectiveness was demonstrated by the significant decrease of TNF- $\alpha$ level by LCC 2 when compared to LCC 1 pretreatment $(\mathrm{P}<0.01)$ (Table 1, Figure $2 \mathrm{~B})$. Ganugula et $\mathrm{al}^{11}$ demonstrated that oral administration of nanocurcumin was proved to be efficient in the pancreatic function improvement after STZ-induced diabetes in mice, in a dose-dependent manner. Multiple assays of several proinflammatory cytokines (IL-1 $\alpha$, G-CSF, IL-10, IL-17A, IL-1 $\beta$, IL-6, TNF- $\alpha$, IL-4, GM-CSF, IFN $\gamma$, IL-2, IL-5, IL-13, IL-12p70) demonstrated that both curcumin and nanocurcumin successfully reduce their production in pancreatic tissue in STZ-induced diabetes in mice. ${ }^{11}$ In vitro study reported that tetrahydrocurcumin (THC), one of the primary metabolites of curcumin, has antioxidant and antiinflammatory activities reducing islet cell apoptosis and improving their viability after being exposed to TNF- $\alpha$, interferon- $\beta$, and IL- $1{ }^{73}$ A clinical study has already demonstrated that oral administration of curcumin combined with piperine could reduce the serum level of TNF- $\alpha$ in diabetic patients, after 12 weeks of treatment. ${ }^{74} \mathrm{~A}$ curcumin derivate, J147, showed the efficacy in ameliorating neuropathy in the streptozotocin-induced mouse model of type $1 \mathrm{DM}^{75}$ Oral curcumin administration proved to reduce diabetic allodynia and hyperalgesia by decreasing the expression of both TNF- $\alpha$ and TNF- $\alpha$ receptor 1 in diabetic rats. ${ }^{76}$ Another therapeutic formula, poly(D,L-lactic-co-glycolic acid)-based curcumin nanoparticles with encapsulated coenzyme Q10, proved to reduce TNF- $\alpha$ due to the increase of its oral bioavailability and therapeutic efficacy. ${ }^{77}$ 
Induced apoptosis of pancreatic beta cells by ROS is associated with the secretion of monocyte chemoattractant protein-1 (MCP-1/CCL2), a member of the C-C chemokine family, and a potent chemotactic factor for monocytes. ${ }^{78,79}$ MCP-1 will recruit more macrophages, dendritic cells, and $\mathrm{T}$ cells into the pancreatic tissue. ${ }^{78}$ In our study, the significant increase of MCP-1 due to STZ administration was substantially reduced by LCC pretreatment, $\mathrm{LCC} 2$ being more efficient than $\mathrm{LCC} 1$ (Table 1, Figure 2F). As an illustration, using an experimental mouse model for diabetes induced by STZ, Cvetkovic et $\mathrm{al}^{80}$ demonstrated that MCP-1 is increased in plasma of diabetic mice and inhibition of this molecule can reduce the insulitis. Admittedly, classically activated macrophages, CD4+, and CD8+ lymphocytes are the first cells that arrive in damaged pancreatic tissue and substantially contribute to pancreatic inflammation and consequently increased pro-inflammatory cytokines and $\mathrm{MCP}-1$ production. ${ }^{72}$ It is considered that one of the most important triggers for pro-inflammatory cytokine production is the activation of NF- $k \beta$, which promotes the expression of pro-inflammatory cytokines. ${ }^{81}$ Curcumin has been proved to be able to modulate the NF-k $\beta$ pathway. ${ }^{82}$ A possible mechanism that enhanced the curcumin effect on pro-inflammatory cytokine levels can be represented by the reduced associated oxidative stress, ${ }^{10}$ which is in turn related to the reduction of NF- $\mathrm{k} \beta$ pathway signalling. ${ }^{83}$

Furthermore, RANTES is a pro-inflammatory chemokine that is a selective attractant for memory $\mathrm{T}$ lymphocytes and monocytes, and plays an important role in inflammation. ${ }^{84}$ Our study results demonstrated a significant reduction in RANTES molecules for both pretreated groups with LCC1 and LCC2, with a better result for LCC2 administration (Table 1, Figure 2G). During insulitis, CD8+ and CD4+ cells are considered to be among the mediators that contribute to beta-cells destruction. ${ }^{85,86}$ The infiltration of the pancreas with T-cells takes place during the inflammatory phase of type $1 \mathrm{DM}^{87} \mathrm{CD} 8+$ lymphocytes are the most abundant cells in the inflammatory infiltrate during insulitis. ${ }^{87}$ Subsequently, the progression of beta-cells destruction is proportional to the infiltration of the pancreatic tissue with CD8+ and pro-inflammatory cytokines, which are partially dependent on the intensity of the oxidative stress. ${ }^{88}$ RANTES may also promote the infiltration of the liver with NK cells during insulitis, being associated with beta-cells destruction. ${ }^{89}$ Even though infiltrating immune cells are considered to hurt beta-cells, there is evidence that they can also contribute to beta-cells proliferation and can delay the DM type 1 onset, but the mechanism is not yet fully understood. ${ }^{89}$ The inflammatory infiltrates accumulation could represent a defense mechanism activated against pancreatic insult, and the preservation of the integrity of this mechanism could constitute a starting point for future therapies. ${ }^{89}$ Identification of the exact functional contribution of immune cells subset, and of cytokine and chemokine overproduction, can contribute to reducing the betacells destruction in type $1 \mathrm{DM}$.

Regarding the mechanism involved, our data results suggest that liposomal curcumin is able to reduce the pro-inflammatory cytokines production (TNF- $\alpha$, IL-6, IL-1 $\alpha$, IL-1 $\beta$, MCP-1, and RANTES) in STZ-induced diabetes in rats, having a favorable functional outcome on pancreatic beta cells function. That was demonstrated by improved plasma levels of C-peptide. Our results showed that the anti-inflammatory effect of curcumin therapy depends on curcumin concentration and their pharmaceutical formula. Once the anti-inflammatory effect or liposomal curcumin has been demonstrated further studies could be conducted to measure the products of metabolism at the level of blood and/or tissues and to elucidate the exact mechanism of curcumin. Furthermore, mechanism studies could be conducted to demonstrate the anti-inflammatory effects of different forms of curcumin (standard, liposomal, nano, micro, etc.). A comparative study regarding various formulas of curcumin would be useful to establish the best delivery system with the highest bioavailability and specific activities on DM experimental models. Moreover, Westen Blood experiments using anti-amylin and antioligomer antibodies could bring more inside on the efficacy of different curcumin formulations and on relation with pancreatic and liver function as well as systemic pro-inflammatory cytokines profile, MCP-1 and RANTES in experimentally induced diabetes mellitus.

\section{Conclusion}

The liposomal curcumin formula was demonstrated to be more efficient than curcumin solution in pancreatic function preservation and is able to reduce the levels of pro-inflammatory cytokines (TNF- $\alpha$, IL-6, IL-1 $\alpha$, IL$1 \beta)$, MCP-1 and RANTES associated with STZ-induced type $1 \mathrm{DM}$ in rats. The decrease in cytokines and improvements of C-peptide level proved better for 
liposomal curcumin formula and acted in a dose-dependent manner. The efficiency of liposomal curcumin administration has to be tested in humans, as adjuvant therapy for type $1 \mathrm{DM}$ patients. Any effort to improve the formula for a better curcumin bioavailability can bring this natural product closer to its use in clinical practice. Natural products therapies added to drugs treatment could constitute a future therapeutic strategy for diabetic patients.

\section{Acknowledgments}

This work was partially supported by the "IuliuHațieganu" University of Medicine and Pharmacy (PCD grant no.1680/27/19.01.2018). The authors thank Dr. Alina Porfire and Dr. Lucia Tefas for the preparation of curcumin solution and liposomal curcumin. The authors are also grateful to Ana Uifalean for helping with laboratory tests and to Molnar Mirel for helping with the rats handling.

\section{Disclosure}

The authors report no conflicts of interest in this work.

\section{References}

1. Sandur SK, Pandey MK, Sung B, et al. Curcumin, demethoxycurcu$\mathrm{min}$, bisdemethoxycurcumin, tetrahydrocurcumin and turmerones differentially regulate anti-inflammatory and anti-proliferative responses through a ROS-independent mechanism. Carcinogenesis. 2007;28 (8):1765-1773. doi:10.1093/carcin/bgm123

2. Mehta J, Rayalam S, Wang X. Cytoprotective effects of natural compounds against oxidative stress. Antioxidants (Basel). 2018;7(10): E147. doi:10.3390/antiox7100147

3. Attiq A, Jalil J, Husain K, et al. Raging the war against inflammation with natural products. Front Pharmacol. 2018;9:976.

4. Shimizu K, Funamoto M, Sunagawa Y, et al. Anti-inflammatory action of curcumin and its use in the treatment of lifestyle-related diseases. Eur Cardiol. 2019;14(2):117-122. doi:10.15420/ecr.2019.17.2

5. Kunnumakkara AB, Bordoloi D, Padmavathi G, et al. Curcumin, the golden nutraceutical: multitargeting for multiple chronic diseases. $\mathrm{Br} J$ Pharmacol. 2017;174(11):1325-1348. doi:10.1111/bph.v174.11

6. Teiten MH, Dicato M, Diederich M. Hybrid curcumin compounds: a new strategy for cancer treatment. Molecules. 2014;19(12):2083920863. doi:10.3390/molecules 191220839

7. Kesharwani SS, Ahmad R, Bakkari MA, et al. Site-directed noncovalent polymer-drug complexes for inflammatory bowel disease (IBD): formulation development, characterization and pharmacological evaluation. J Control Release. 2018;290:165-179. doi:10.1016/j. jconrel.2018.08.004

8. Boarescu PM, Chirilă I, Bulboacă AE, et al. Effects of curcumin nanoparticles in isoproterenol-induced myocardial infarction. Oxid Med Cell Longev. 2019;2019:Article ID 7847142. doi:10.1155/2019/ 7847142

9. Boarescu PM, Boarescu I, Bocșan IC, et al. Curcumin nanoparticles protect against isoproterenol induced myocardial infarction by alleviating myocardial tissue oxidative stress, electrocardiogram, and biological changes. Molecules. 2019;24(15):E2802. doi:10.3390/ molecules 24152802
10. Bulboacă AE, Porfire AS, Tefas LR, et al. Liposomal curcumin is better than curcumin to alleviate complications in experimental diabetic mellitus. Molecules. 2019;24(5):846. doi:10.3390/molecules24050846

11. Ganugula R, Arora M, Jaisamut P, et al. Nano-curcumin safely prevents streptozotocin-induced inflammation and apoptosis in pancreatic beta cells for effective management of Type 1 diabetes mellitus. $\mathrm{Br} J$ Pharmacol. 2017;174(13):2074-2084. doi:10.1111/bph.13816

12. Kumar S, Kesharwani SS, Mathur H, et al. Molecular complexation of curcumin with $\mathrm{pH}$ sensitive cationic copolymer enhances the aqueous solubility, stability and bioavailability of curcumin. Eur $J$ Pharm Sci. 2016;82:86-96. doi:10.1016/j.ejps.2015.11.010

13. Lopresti AL. The problem of curcumin and its bioavailability: could its gastrointestinal influence contribute to its overall health-enhancing effects? Adv Nutr. 2018;9(1):41-50. doi:10.1093/advances/ nmx011

14. Feng T, Wei Y, Lee RJ, et al. Liposomal curcumin and its application in cancer. Int J Nanomedicine. 2017;12:6027-6044. doi:10.2147/IJN

15. Raimondo S, Giavaresi G, Lorico A, et al. Extracellular vesicles as biological shuttles for targeted therapies. Int J Mol Sci. 2019;20(8): E1848. doi:10.3390/ijms20081848

16. Schiborr C, Eckert GP, Rimbach G, et al. A validated method for the quantification of curcumin in plasma and brain tissue by fast narrowbore high-performance liquid chromatography with fluorescence detection. Anal Bioanal Chem. 2010;397(5):1917-1925. doi:10.10 07/s00216-010-3719-3

17. Liliemark E, Liliemark J, Kållberg N, et al. Studies of the organ distribution in mice of teniposide liposomes designed for treatment of diseases in the mononuclear phagocytic system. Pediatr Res. 1995;38 (1):7-10. doi:10.1203/00006450-199507000-00002

18. Elguindy NM, Awad D, Zaky A, et al. Liposomal curcumin improves insulin resistance in type 2 diabetic rats by upregulating hepatic GLUT-2. J Diabetes Metab. 2017;8:8.

19. Padgett LE, Broniowska KA, Hansen PA, et al. The role of reactive oxygen species and proinflammatory cytokines in type 1 diabetes pathogenesis. Ann N Y Acad Sci. 2013;1281:16-35. doi:10.1111/ j.1749-6632.2012.06826.x

20. Willcox A, Gillespie KM. Histology of type 1 diabetes pancreas. Methods Mol Biol. 2016;1433:105-117.

21. Morgan NG, Richardson SJ. Fifty years of pancreatic islet pathology in human type 1 diabetes: insights gained and progress made. Diabetologia. 2018;61(12):2499-2506. doi:10.1007/s00125-018-4731-y

22. Zhang JM, An J. Cytokines, inflammation, and pain. Int Anesthesiol Clin. 2007;45(2):27-37. doi:10.1097/AIA.0b013e318034194e

23. Qu D, Liu J, Lau CW, et al. IL-6 in diabetes and cardiovascular complications. Br J Pharmacol. 2014;171(15):3595-3603. doi:10.11 11/bph. 12713

24. Panee J. Monocyte chemoattractant protein 1 (MCP-1) in obesity and diabetes. Cytokine. 2012;60(1):1-12. doi:10.1016/j.cyto.2012. 06.018

25. Mora C, Navarro JF. Inflammation and diabetic nephropathy. Curr Diab Rep. 2006;6(6):463-468. doi:10.1007/s11892-006-0080-1

26. Navarro-Gonzalez JF, Jarque A, Muros M, et al. Tumor necrosis factor-alpha as a therapeutic target for diabetic nephropathy. Cytokine Growth Factor Rev. 2009;20(2):165-173. doi:10.1016/j. cytogfr.2009.02.005

27. Qiao YC, Chen YL, Pan YH, et al. The change of serum tumor necrosis factor alpha in patients with type 1 diabetes mellitus: a systematic review and meta-analysis. PLoS One. 2017;12(4): e0176157. doi:10.1371/journal.pone.0176157

28. Koj A. Initiation of acute phase response and synthesis of cytokines. Biochim Biophys Acta. 1996;1317(2):84-94. doi:10.1016/S0925-44 39(96)00048-8

29. Kristiansen OP, Mandrup-Poulsen T. Interleukin- 6 and diabetes: the good, the bad, or the indifferent? Diabetes. 2005;54(Suppl 2):S114 124. doi:10.2337/diabetes.54.suppl_2.S114 
30. Jain SK, Rains J, Croad J, et al. Curcumin supplementation lowers TNF-alpha, IL-6, IL-8, and MCP-1 secretion in high glucose-treated cultured monocytes and blood levels of TNF-alpha, IL-6, MCP-1, glucose, and glycosylated hemoglobin in diabetic rats. Antioxid Redox Signal. 2009;11:241-249. doi:10.1089/ars.2008.2140

31. Kolattukudy PE, Niu J. Inflammation, endoplasmic reticulum stress, autophagy, and the monocyte chemoattractant protein-1/CCR2 pathway. Circ Res. 2012;110(1):174-189. doi:10.1161/CIRCRESAHA.111.243 212

32. Sarkar SA, Lee CE, Victorino F, et al. Expression and regulation of chemokines in murine and human type 1 diabetes. Diabetes. 2012;61 (2):436-446. doi:10.2337/db11-0853

33. Scarim AL, Heitmeier MR, Corbett JA. Irreversible inhibition of metabolic function and islet destruction after a $36 \mathrm{hr}$ exposure to interleukin-1beta. Endocrinology. 1997;138:5301-5307. doi:10.1210/ endo.138.12.5583

34. Hughes KJ, Chambers KT, Meares GP, et al. Nitric oxides mediates a shift from early necrosis to late apoptosis in cytokine-treated betacells that is associated with irreversible DNA damage. Am J Physiol Endocrinol Metabol. 2009;297:E1187-E1196. doi:10.1152/ajpendo. 00214.2009

35. Reddy S, Wu D, Elliott RB. Low doses streptozotocin causes diabetes in severe combined immunodeficient (SCID) mice without immune cell infiltration of the pancreatic islets. Autoimmunity. 1995;20(2):8392. doi:10.3109/08916939509001931

36. Bulboacă A, Bolboacă SD, Suci S. Protective effect of curcumin in fructose-induced metabolic syndrome and in streptozotocin-induced diabetes in rats. Iran J Basic Med Sci. 2016;19(6):585-593.

37. Tefas LR, Sylvester B, Tomuta I, et al. Development of antiproliferative long-circulating liposomes co-encapsulating doxorubicin and curcumin, through the use of a quality-by-design approach. Drug Des Devel Ther. 2017;11:1605-1621. doi:10.2147/DDDT

38. Bulboacă AE, Bolboacă SD, Stănescu IC, et al. The effect of intravenous administration of liposomal curcumin in addition to sumatriptan treatment in an experimental migraine model in rats. Int $J$ Nanomedicine. 2018;13:3093-3103. doi:10.2147/IJN

39. King AJ. The use of animal models in diabetes research. $\mathrm{Br} J$ Pharmacol. 2012;166(3):877-894. doi:10.1111/j.1476-5381.2012.01 911.x

40. Elbialy NS, Aboushoushah SF, Alshammari WW. Long-term biodistribution and toxicity of curcumin capped iron oxide nanoparticles after single-dose administration in mice. Life Sci. 2019;230:76-83. doi:10.1016/j.lfs.2019.05.048

41. Shahani K, Swaminathan SK, Freeman D, et al. Injectable sustained release microparticles of curcumin: a new concept for cancer chemoprevention. Cancer Res. 2010;70(11):4443-4452. doi:10.1158/00085472.CAN-09-4362

42. Anchi P, Khurana A, Swain D, et al. Dramatic improvement in pharmacokinetic and pharmacodynamic effects of sustain release curcumin microparticles demonstrated in experimental type 1 diabetes model. Eur J Pharm Sci. 2019;130:200-214. doi:10.1016/j. ejps.2019.02.002

43. Melo A, Leite-Almeida H, Ferreira C, et al. Exposure to ketamine anesthesia affects rat impulsive behavior. Front Behav Neurosci. 2016;10:226. doi:10.3389/fnbeh.2016.00226

44. Nordquist L, Johansson M. Proinsulin C-peptide: friend or foe in the development of diabetes-associated complications? Vasc Health Risk Manag. 2008;4(6):1283-1288. doi:10.2147/VHRM.S3955

45. Rubenstein AH, Kuzuya H, Horwitz DL. Clinical significance of circulating C-peptide in diabetes mellitus and hypoglycemic disorders. Arch Intern Med. 1977;137(5):625-632. doi:10.1001/ archinte.1977.03630170047014

46. Bonser AM, Garcia-Webb P. C-peptide measurement: methods and clinical utility. Crit Rev Clin Lab Sci. 1984;19(4):297-352. doi:10.3109/10408368409165766
47. Yosten GLC, Maric-Bilkan C, Luppi P, et al. Physiological effects and therapeutic potential of proinsulin C-peptide. Am J Physiol Endocrinol Metab. 2014;307:E955-E968. doi:10.1152/ajpendo.001 30.2014

48. Kitabchi AE. Proinsulin and C-peptide: a review. Metabolism. 1977;26(5):547-587. doi:10.1016/0026-0495(77)90099-3

49. Leyva-García E, Lara-Martínez R, Morán-Zanabria L, et al. Novel insight into streptozotocin-induced diabetic rats from the protein misfolding perspective. Sci Rep. 2017;7(1):11552. doi:10.1038/s41 598-017-11776-y

50. Wójcikowski C, Maier V, Dominiak K, et al. Effects of synthetic rat C-peptide in normal and diabetic rats. Diabetologia. 1983;25:288290. doi:10.1007/BF00279945

51. Sato Y, Oshida Y, Han YQ, et al. C-peptide fragments stimulate glucose utilization in diabetic rats. Cell Mol Life Sci. 2004;61:727732. doi:10.1007/s00018-003-3460-6

52. Wu W, Oshida Y, Yang WP, et al. Effect of C-peptide administration on whole body glucose utilization in STZ-induced diabetic rats. Acta Physiol Scand. 1996;157:253-258. doi:10.1046/j.1365-201X.1996.48 9236000.x

53. Johansson BL, Linde B, Wahren J. Effects of C-peptide on blood flow, capillary diffusion capacity and glucose utilization in the exercising forearm of type 1 (insulin-dependent) diabetic patients. Diabetologia. 1992;35:1151-1158. doi:10.1007/BF00401369

54. Ghorbani A, Omrani GR, Hadjzadeh MA, Varedi M. Proinsulin $\mathrm{C}$-peptide inhibits lipolysis in diabetic rat adipose tissue through phosphodiesterase-3B enzyme. Horm Metab Res. 2013;45:221-225. doi:10.1055/s-0032-1323764

55. Yu SS, Kitbachi AE. Biological activity of proinsulin and related polypeptides in the fat tissue. J Biol Chem. 1973;248:3753-3761.

56. Wallerath T, Kunt T, Forst T, et al. Stimulation of endothelial nitric oxide synthase by proinsulin C-peptide. Nitric Oxide. 2003;9:95-102. doi:10.1016/j.niox.2003.08.004

57. Sjöberg S, Gunnarsson R, Gjötterberg M, et al. Residual insulin production, glycaemic control and prevalence of microvascular lesions and polyneuropathy in long-term type 1 (insulin-dependent) diabetes mellitus. Diabetologia. 1987;30:208-213. doi:10.1007/ BF00270417

58. Rebsomen L, Pitel S, Boubred F, et al. C-peptide replacement improves weight gain and renal function in diabetic rats. Diabetes Metab. 2006;32:223-228. doi:10.1016/S1262-3636(07)70272-0

59. Klein R, Moss SE, Klein BE, et al. Wisconsin Epidemiologic Study of Diabetic Retinopathy. XII. Relationship of C-peptide and diabetic retinopathy. Diabetes. 1990;39(11):1445-1450. doi:10.2337/diab.39. 11.1445

60. Kuo JZ, Guo X, Klein R, et al. Association of fasting insulin and C peptide with diabetic retinopathy in Latinos with type 2 diabetes. BMJ Open Diabetes Res Care. 2014;2(1):e000027. doi:10.1136/ bmjdrc-2014-000027

61. Al-Rasheed NM, Willars GB, Brunskill NJ. C-peptide signals via Galpha $\mathrm{i}$ to protect against TNF-alpha-mediated apoptosis of opossum kidney proximal tubular cells. J Am Soc Nephrol. 2006;17:986995. doi:10.1681/ASN.2005080797

62. Maezawa Y, Yokote K, Sonezaki K, et al. Influence of C-peptide on early glomerular changes in diabetic mice. Diabetes Metab Res Rev. 2006;22:313-322. doi:10.1002/(ISSN)1520-7560

63. Sima AA, Zhang W, Sugimoto K, et al. C-peptide prevents and improves chronic type I diabetic polyneuropathy in the BB/Wor rat. Diabetologia. 2001;44:889-897. doi:10.1007/s00125 0100570

64. Sima AA, Li ZG. The effect of C-peptide on cognitive dysfunction and hippocampal apoptosis in type 1 diabetic rats. Diabetes. 2005;54:1497-1505. doi:10.2337/diabetes.54.5.1497

65. Ghorbani A, Shafiee-Nick R. Pathological consequences of C-peptide deficiency in insulin-dependent diabetes mellitus. World J Diabetes. 2015;6(1):145-150. doi:10.4239/wjd.v6.i1.145 
66. Scalia R, Coyle KM, Levine BJ, et al. C-peptide inhibits leukocyteendothelium interaction in the microcirculation during acute endothelial dysfunction. Faseb J. 2000;14:2357-2364. doi:10.10 96/fj.00-0183com

67. Fatima N, Faisal SM, Zubair S, et al. Role of pro-inflammatory cytokines and biochemical markers in the pathogenesis of type 1 diabetes: correlation with age and glycemic condition in diabetic human subjects. PLoS One. 2016;11(8):e0161548. doi:10.1371/journal.pone. 0161548

68. Hoeldtke RD, Bryner KD, McNeill DR, et al. Oxidative stress and insulin requirements in patients with recent-onset type 1 diabetes. $J$ Clin Endocrinol Metab. 2003;88:1624-1628. doi:10.1210/jc.2002021525

69. Teodoro JS, Gomes AP, Varela AT, et al. Uncovering the beginning of diabetes: the cellular redox status and oxidative stress as starting players in hyperglycemic damage. Mol Cell Biochem. 2013; 376:103-110. doi:10.1007/s11010-012-1555-9

70. Griffiths HR, Gao D, Pararasa C. Redox regulation in metabolic programming and inflammation. Redox Biol. 2017;12:50-57. doi:10. 1016/j.redox.2017.01.023

71. Espinoza-Jiménez A, Peón AN, Terrazas LI. Alternatively activated macrophages in types 1 and 2 diabetes. Mediators Inflamm. 2012;2012:815953. doi:10.1155/2012/815953

72. Rabinovitch A, Suarez-Pinzon WL. Cytokines and their roles in pancreatic islet $\beta$-cell destruction and insulin-dependent diabetes mellitus. Biochem Pharmacol. 1998;55(8):1139-1149. doi:10.1016/ S0006-2952(97)00492-9

73. Kim SS, Jang HJ, Oh MY, et al. Tetrahydrocurcumin enhances islet cell function and attenuates apoptosis in mouse islets. Transplant Proc. 2018;50(9):2847-2853. doi:10.1016/j.transproceed.2018.03.033

74. Panahi Y, Khalili N, Sahebi E, et al. Curcuminoids plus piperine modulate adipokines in type 2 diabetes mellitus. Curr Clin Pharmacol. 2017;12(4):253-258. doi:10.2174/1574884713666180104095641

75. Daugherty DJ, Marquez A, Calcutt NA, et al. A novel curcumin derivative for the treatment of diabetic neuropathy. Neuropharmacology. 2018;129:26-35. doi:10.1016/j.neuropharm.2017.11.007

76. Li Y, Zhang Y, Liu DB, et al. Curcumin attenuates diabetic neuropathic pain by downregulating TNF- $\alpha$ in a rat model. Int J Med Sci. 2013;10(4):377-381. doi:10.7150/ijms.5224

77. Devadasu VR, Wadsworth RM, Kumar MN. Protective effects of nanoparticulate coenzyme Q10 and curcumin on inflammatory markers and lipid metabolism in streptozotocin-induced diabetic rats: a possible remedy to diabetic complications. Drug Deliv Transl Res. 2011;1(6):448-455. doi:10.1007/s13346-011-0041-3
78. Martin AP, Rankin S, Pitchford S, et al. Increased expression of CCL2 in insulin-producing cells of transgenic mice promotes mobilization of myeloid cells from the bone marrow, marked insulitis, and diabetes. Diabetes. 2008;57(11):3025-3033. doi:10.2337/db08-0625

79. Deshmane SL, Kremlev S, Amini S, et al. Monocyte chemoattractant protein-1 (MCP-1): an overview. J Interferon Cytokine Res. 2009;29 (6):313-326. doi:10.1089/jir.2008.0027

80. Cvetkovic I, Al-Abed Y, Miljkovic D, et al. Critical role of macrophage migration inhibitory factor activity in experimental autoimmune diabetes. Endocrinology. 2005;146(7):2942-2951. doi:10.1210/ en.2004-1393

81. Cnop M, Welsh N, Jonas JC, et al. Mechanisms of pancreatic betacell death in type 1 and type 2 diabetes: many differences, few similarities. Diabetes. 2005;54(Suppl 2):S97-107. doi:10.2337/diabetes.54.suppl 2.S97

82. Pavan AR, Silva GD, Jornada DH, et al. Unraveling the anticancer effect of curcumin and resveratrol. Nutrients. 2016;8(11):E628. doi: $10.3390 /$ nu8110628

83. Marshall HE, Merchant K, Stamler JS. Nitrosation and oxidation in the regulation of gene expression. Faseb J. 2000;14(13):1889-1900. doi:10.1096/fj.00.011rev

84. Mlynarski WM, Placha GP, Wolkow PP, et al. Risk of diabetic nephropathy in type 1 diabetes is associated with functional polymorphisms in RANTES receptor gene (CCR5): a sex-specific effect. Diabetes. 2005;54(11):3331-3335. doi:10.2337/diabetes.54.11.3331

85. Somoza N, Vargas F, Roura-Mir C, et al. Pancreas in recent onset insulin-dependent diabetes mellitus. Changes in HLA, adhesion molecules and autoantigens, restricted $\mathrm{T}$ cell receptor $\mathrm{V}$ beta usage, and cytokine profile. J Immunol. 1994;153(3):1360-1377.

86. Morgan NG, Leete P, Foulis AK, Richardson SJ. Islet inflammation in human type 1 diabetes mellitus. IUBMB Life. 2014;66(11):723734. doi:10.1002/iub.v66.11

87. Willcox A, Richardson SJ, Bone AJ, et al. Analysis of islet inflammation in human type 1 diabetes. Clin Exp Immunol. 2009;155 (2):173-181. doi:10.1111/cei.2009.155.issue-2

88. Jörns A, Günther A, Hedrich $\mathrm{HJ}$, et al. Immune cell infiltration, cytokine expression, and beta-cell apoptosis during the development of type 1 diabetes in the spontaneously diabetic LEW.1AR1/ZtmIDDM rat. Diabetes. 2005;54(7):2041-2052. doi:10.2337/diabetes. 54.7.2041

89. Dirice E, Kahraman S, Jiang W, et al. Soluble factors secreted by T cells promote $\beta$-cell proliferation. Diabetes. 2014;63(1):188-202. doi: $10.2337 / \mathrm{db} 13-0204$
International Journal of Nanomedicine

\section{Publish your work in this journal}

The International Journal of Nanomedicine is an international, peerreviewed journal focusing on the application of nanotechnology in diagnostics, therapeutics, and drug delivery systems throughout the biomedical field. This journal is indexed on PubMed Central, MedLine, CAS, SciSearch ${ }^{\mathbb{B}}$, Current Contents ${ }^{\mathbb{B}} /$ Clinical Medicine, $^{2}$
Journal Citation Reports/Science Edition, EMBase, Scopus and the Elsevier Bibliographic databases. The manuscript management system is completely online and includes a very quick and fair peer-review system, which is all easy to use. Visit http://www.dovepress.com/ testimonials.php to read real quotes from published authors. 